\title{
Hydroxychloroquine retinal toxicity in two patients with \\ dermatology conditions
}

Tanya Kowalski ${ }^{1}$ BBiomed, MD

Christopher Baker ${ }^{2}$ FACD

Heather G Mack ${ }^{3,4 *}$ PhD FRANZCO

1 Alfred Hospital, Melbourne

2 St Vincent's Hospital, Melbourne

3 Melbourne Health, Melbourne

4 Centre for Eye Research Australia

*Corresponding author

2/232 Victoria Parade

East Melbourne 3002

Phone 0394160695

Fax 0394161816

Emailhmack@eyesurgery.com.au

No conflicts of interest.

No funding sources.

Manuscript Word Count: 1143

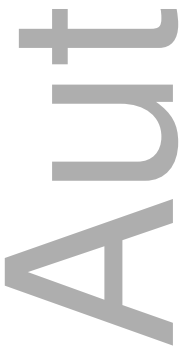

This is the author manuscript accepted for publication and has undergone full peer review but has not been through the copyediting, typesetting, pagination and proofreading process, which may lead to differences between this version and the Version of Record. Please cite this article as doi: $10.1111 /$ AJD.12827

This article is protected by copyright. All rights reserved 


\section{Article type : Brief Reports}

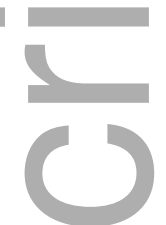

\section{Abstract}

A 58 year-old female developed hydroxychloroquine retinal toxicity with bull's-eye maculopathy after treatment for lichen sclerosus $(3.7-7.3 \mathrm{mg} / \mathrm{kg}$, treatment duration 6 years). A 69 year-old female developed hydroxychloroquine retinal toxicity with an essentially normal fundus, diagnosed on ancillary testing, after treatment for lichen planopilaris (11.4 mg/kg, treatment duration 29 months). Recently revised guidelines lowered the recommended maximum daily dose to $5 \mathrm{mg} / \mathrm{kg}$ total body weight. There is no treatment for hydroxychloroquine retinal toxicity, so appropriate monitoring is imperative. All members of a patient's multidisciplinary team should be self-informed about the ocular risks of hydroxychloroquine and the role of appropriate monitoring in reducing the risk of visual loss.

\section{Keywords}

Hydroxychloroquine

Toxicity

Retina

Lichen sclerosus

Lichen planopilaris 


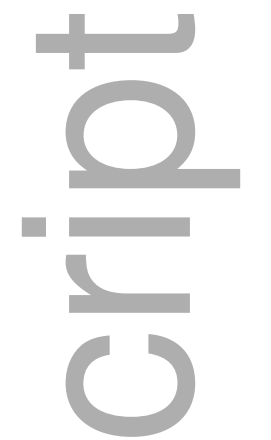

\section{Learning Points}

1. Patients developing hydroxychloroquine retinopathy are frequently asymptomatic and may have minimal retinal changes on fundoscopy. Patients receiving hydroxychloroquine are recommended to have ophthalmic examination at baseline, and annually after 5 years of continuous dosing, or earlier if symptoms develop or risk factors (dose $>5 \mathrm{mg} / \mathrm{kg}$ actual body weight, renal disease, tamoxifen use, pre-existing macular disease) are present.

2. Recent international ophthalmology recommendations have lowered the maximum recommended hydroxychloroquine dose from $6.5 \mathrm{mg} / \mathrm{kg}$ lean body weight to $5.0 \mathrm{mg} / \mathrm{kg}$ actual body weight.

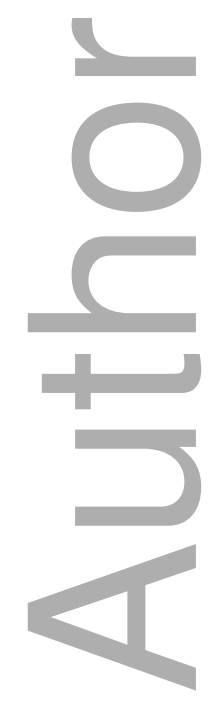




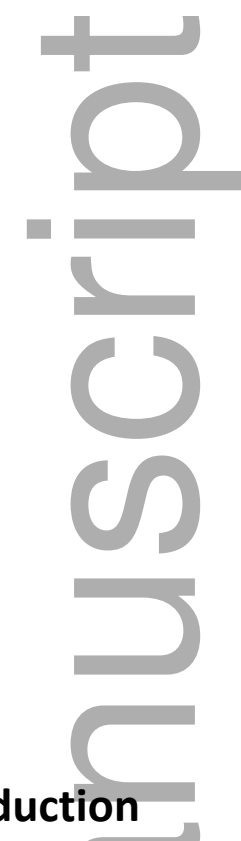

Hydroxychloroquine (HCQ) is an anti-malarial medication used in treating dermatological ${ }^{1}$ and rheumatological inflammatory conditions. The mechanism of action is not clear, but is known to be multifactorial and includes immunomodulatory, anti-inflammatory and antiproliferative effects. Treatment is generally well tolerated but can be complicated by adverse events in up to $25 \%$ of patients. ${ }^{2}$ Dermatologic, gastro-intestinal, and neurologic side effects are the most common. ${ }^{2}$ We report two patients who developed retinal toxicity while being treated for dermatologic conditions and discuss recent changes to screening guidelines.

\section{Patient 1}

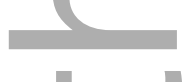

An asymptomatic 58-year-old Caucasian woman presented for ophthalmic assessment in 2007. She had taken HCQ between 1996 and 2002 for lichen sclerosus (dose 400mg/day, $7.3 \mathrm{mg} / \mathrm{kg}$ actual body weight). HCQ was ceased in 2002 on ophthalmic advice when bull's eye maculopathy developed, but restarted by another practitioner in 2004 and continued until presentation (dose $200 \mathrm{mg} / \mathrm{day}, 3.7 \mathrm{mg} / \mathrm{kg}$ actual body weight). Her cumulative dose was $>1160$ g). She had left optic neuritis in 1995, with chronic reduced vision. She had asthma, hypertension and hypercholesterolaemia, but no renal failure and did not smoke 
cigarettes. Her medications were methotrexate, fluticasone/salmeterol, tiotropium bromide, telmisartan and atorvastatin; she did not take tamoxifen. Visual acuities were right $6 / 6$, left $6 / 18$. Fundus examination revealed bull's eye macular change bilaterally (Figure 1 A-C, right eye illustrated). HCQ retinal toxicity was diagnosed and HCQ was again recommended to be ceased. At follow-up in 2016 visual acuities were right 6/12 and left $6 / 24$, and progressive macular atrophy was noted in both eyes.

\section{Patient 2}

A 69-year-old Caucasian woman complained of a blurred central patch in vision in both eyes. She had taken HCQ (500 mg/day, $11.4 \mathrm{mg} / \mathrm{kg}$ actual body weight, cumulative dose $>440 \mathrm{~g}$ ) for 29 months for lichen planopilaris, but self-ceased this when she noted visual symptoms. She had no significant past ophthalmic or medical history, did not smoke cigarettes, and took no regular medications. Visual acuity was $6 / 6$ both eyes. Fundus examination showed very mild macular granularity, however automated visual field testing (Humphrey, Zeiss Meditec, Germany) demonstrated a dense central scotoma and optical coherence tomography (Cirrus, Zeiss Meditec, Germany; OCT) scanning demonstrated parafoveal thinning in both eyes (Figure 1 D-F, left eye illustrated).

\section{Main Text}

Our two patients with dermatological conditions developed HCQ toxicity whilst being treated above the past and current dosing recommendations by ophthalmology societies, ${ }^{3-5}$ dermatologists ${ }^{1}$ and the manufacturer. ${ }^{6}$ Patient 1 had HCQ restarted despite diagnosed toxicity, demonstrating the necessity of good communication between all practitioners involved in a patient's care. Patient 2 developed toxicity after only 29 months, similar to previous reports with very high doses of HCQ for cancer therapy, ${ }^{7}$ raising the issues of the role of baseline screening and screening during the first five years of treatment.

Early ophthalmology reports suggested the risk of HCQ retinopathy was low, ${ }^{8}$ approximately $0.5 \%$ after a mean of 8.7 years of treatment. However, a recent large study of 2361 patients who had received HCQ treatment for more than 5 years suggests much higher risk than previously recognised, with retinopathy occurring in around $7.5 \%$ patients, and up to $20 \%$ of patients who have received HCQ for 20 years. ${ }^{9}$ This pivotal study led to revision of 
international HCQ screening recommendations, ${ }^{4,5}$ although it should be noted that the study population was limited to members of the Kaiser Permanente Northern California health organisation.

The mechanism of HCQ toxicity is not understood. HCQ retinopathy is typically asymptomatic until late stages; occasionally patients report difficulty reading or positive scotomata (e.g. Patient 2). The condition is bilateral and usually symmetrical. Retinal damage is first noted parafoveal on automated field testing of macular function $\left(10^{\circ}\right.$ field), OCT scanning or fundus autofluorescence imaging (e.g. Patient 2). In late stages bull's eye pattern of macular atrophy, sparing the fovea, develops (e.g. Patient 1). Retinopathy in Asians may be more peripheral than in Caucasians. The sensitivity of field testing and OCT scanning are estimated to be $85.7 \%$ and $78.6 \%$ respectively, and specificity $92.5 \%$ and $98.1 \%$ respectively. Positive predictive values are less than $30 \%$ for all estimates of $\mathrm{HCQ}$ retinopathy prevalence. Negative predictive values are $>99 \% .{ }^{10}$ Risk factors for toxicity include daily dose, cumulative dose, renal failure, concurrent use of tamoxifen and preexisting macular disease. There is no data on cigarette smoking as a risk factor. The only available treatment is drug cessation, however progressive visual loss despite drug cessation occurs commonly (e.g. Patient 1), and has been well described when the diagnosis is made using OCT or visual fields, well before onset of late retinal changes on fundoscopy.

Until recently a dose of $400 \mathrm{mg}$ daily, $6.5 \mathrm{mg} / \mathrm{kg}$ lean (ideal) body weight or cumulative dose $<1000 \mathrm{~g}$ was considered safe. ${ }^{3}$ Both our patients were dosed above this level. Revised international ophthalmic guidelines, ${ }^{4,5}$ also adopted in Australia, recommend lowering of the maximum dose to $5 \mathrm{mg} / \mathrm{kg}$ actual body weight. The revised guidelines no longer consider cumulative dose as this was not found to be a predictor of toxicity. Due to the long action of $\mathrm{HCQ}$, lower average daily doses can be achieved by alternate day dosing if necessary. Patients are recommended to have ophthalmic examination at baseline, and then annually after 5 years of treatment, with earlier review if symptoms develop earlier or risk factors are present. Minimum screening requires fundus examination, OCT macular scanning including vertical line scan, and automated macular perimetry.

Fundus photography, fundus autofluorescence and multifocal electroretinography are optional. Screening in Asian patients needs to consider more peripheral retinal involvement. 


\section{Conclusion}

In an age where multidisciplinary care is evolving, all team members involved in monitoring disease and prescribing treatment should be self-informed about the ocular risks of HCQ and the role of contemporary retinal monitoring in reducing the risk of HCQ visual loss.

\section{References}

1. Fernandez AP. Updated recommendations on the use of hydroxychloroquine in dermatologic practice. J Am Acad Dermatol 2017; 76: 1176-1182.

2. Mittal L, Zhang L, Feng R, Werth VP. Antimalarial drug toxicities in patients with cutaneous lupus and dermatomyositis. J Am Acad Dermatol 2017; https://doi.org/10.1016/i.jaad.2017.2017.09.061.

3. Marmor MF, Kellner U, Lai TY et al. Revised recommendations on screening for chloroquine and hydroxychloroquine retinopathy. Ophthalmol 2011; 118:415-422. 4. Marmor MF, Kellner U, Lai TY et al. Recommendations on screening for chloroquine and hydroxychloroquine retinopathy (2016 revision). Ophthalmol 2016; 123: 1386-1394.

5. The Royal College of Ophthalmologists. Hydroxychloroquine and chloroquine retinopathy: recommendations on screening. February 2018. Available from https://www.rcophth.ac.uk/wp-content/uploads/2018/02/Hydroxychloroquine-andChloroquine-Retinopathy-Screening-Guideline.pdf. Last accessed 27/2/2018.

4

6. Sanofi. Product information. Plaquenil - hydroxychloroquine sulfate. 2014. Available from http://products.sanofi.com.au/aus_pi_plaquenil_20140402.pdf. Last accessed 27/2/2018.

7. Leung LS' Neal JW' Wakelee HA' Sequist LV' Marmor MF. Rapid onset of retinal toxicity from high-dose hydroxychloroquine given for cancer therapy. Am J Ophthalmol 2015; 160: 799-805.

7

This article is protected by copyright. All rights reserved 
8. Mavrikakis I, Sfikakis PP, Mavrikakis E, Rougas K, Nikolaou A, Kostopoulos C, et al. The incidence of irreversible retinal toxicity in patients treated with hydroxychloroquine: a reappraisal. Ophthalmology 2003; 110: 1321-6.

9. Melles RB, Marmor MF. The risk of toxic retinopathy in patients on long-term hydroxychloroquine therapy. JAMA Ophthalmol 2014; 132: 1453-1460.

10. Browning DJ, Lee C. Relative sensitivity and specificity of 10-2 visual fields, multifocal electroretinography, and spectral domain optical coherence tomography in detecting hydroxychloroquine and chloroquine retinopathy. Clin Ophthalmol 2014; 8: 1389-1399.

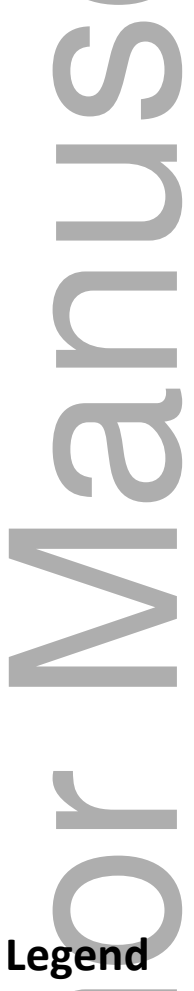

Figure 1: $A-C$, The right eye of a 58 year-old Caucasian female with lichen sclerosus and hydroxychloroquine retinopathy: A) Colour fundus photograph showing bull's eye macular atrophy. B) Automated visual field testing ( $10^{\circ}$ field) showing a ring scotoma with inferior sparing. C) Optical coherence tomography (OCT, vertical cut) showing parafoveal retinal pigment epithelial and photoreceptor thinning (arrows, 'flying saucer sign'), with inset OCT en face view showing generalised macular thinning.

$D-F$, The left eye of a 69 year-old Caucasian female with lichen planopilaris and hydroxychloroquine retinopathy: D) Colour fundus photograph showing mild macular granularity. E) Automated visual field testing ( $10^{\circ}$ field) showing a central scotoma. F) OCT 
scanning (vertical cut) showing parafoveal retinal pigment epithelial and photoreceptor thinning (arrows), with inset OCT en face view showing parafoveal retinal thinning.

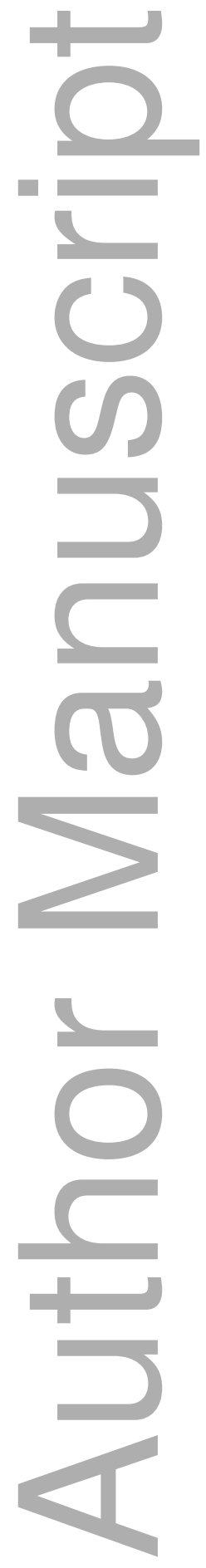

This article is protected by copyright. All rights reserved 

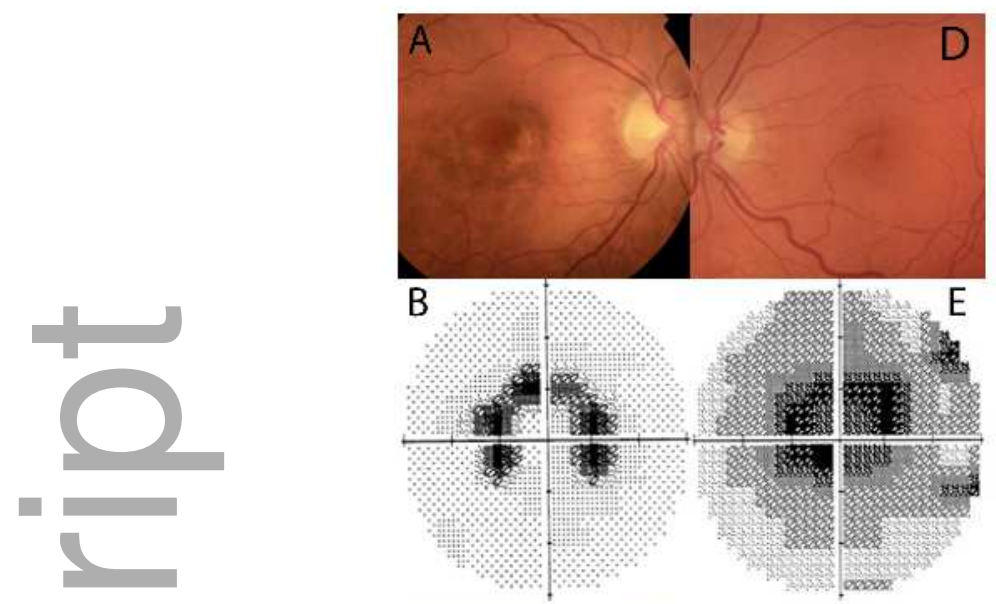

$\square$
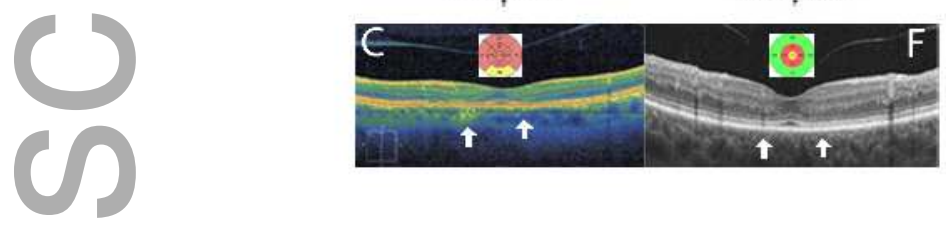

ajd_12827_f1.jpg

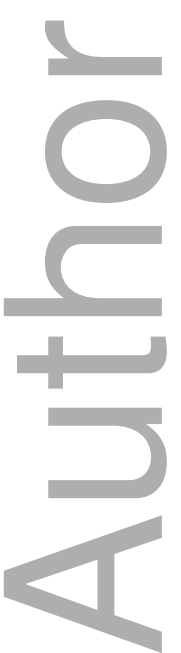

This article is protected by copyright. All rights reserved 


\section{University Library}

\section{- M M I N E R VA A gateway to Melbourne's research publications}

Minerva Access is the Institutional Repository of The University of Melbourne

Author/s:

Kowalski, T;Baker, C;Mack, HG

Title:

Hydroxychloroquine retinal toxicity in two patients with dermatological conditions.

Date:

2018-11

Citation:

Kowalski, T., Baker, C. \& Mack, H. G. (2018). Hydroxychloroquine retinal toxicity in two patients with dermatological conditions.. Australas J Dermatol, 59 (4), pp.e266-e268. https:// doi.org/10.1111/ajd.12827.

Persistent Link:

http://hdl.handle.net/11343/284113 